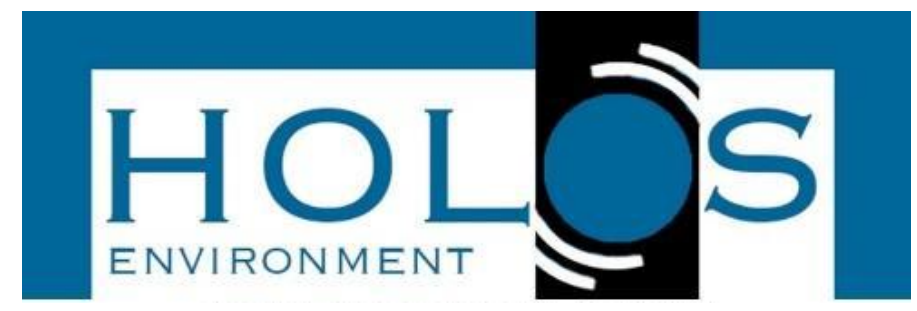

\title{
AVALIAÇÃO DA SUBSTITUIÇÃO DE ALTOS TEORES DE CIMENTO PORTLAND POR CINZA DE CASCA DE ARROZ QUANDO APLICADOS À PAVIMENTAÇÃO
}

\section{EVALUATION OF ORDINARY PORTLAND CEMENT SUBSTITUTION BY RICE HUSK ASH WHEN APPLIED ON THE PAVING}

\author{
Jupira Almeida ${ }^{1}$; Alessandro Graeff Goldoni ${ }^{1}$; Gustavo Dias Miguel²; Bruna Soares de \\ Azevedo ${ }^{1}$
}

Artigo recebido em: 25/05/2020 e aceito para publicação em: 14/08/2020.

DOI: http:/dx.doi.org/10.14295/holos.v20i4.12398

\begin{abstract}
Resumo: O cimento atualmente é um dos produtos mais consumidos mundialmente da mesma forma, é um dos maiores responsáveis pela emissão de dióxido de carbono $\left(\mathrm{CO}_{2}\right)$ na atmosfera resultado da forma em que é produzido. Com isto, surge a necessidade urgente da substituição deste ou ao menos da redução de seu consumo. A tendência global é que a sociedade parta para um consumo e reaproveitamento de seus próprios resíduos gerados tanto pela necessidade em virtude de escassez de matéria-prima natural quanto pela inevitabilidade de tratamento destes que necessitam de um correto descarte. Desta forma, inúmeros materiais alternativos vêm surgindo suscetíveis a substituição dos até então convencionas, que é o caso da Cinza de Casca de Arroz - CCA proveniente da queima em leito fluidizado do material orgânico remanescente da descasca do arroz. No atual trabalho, é verificada a substituição parcial e total do cimento por cinza de casca de arroz avaliando seu potencial de utilização na pavimentação. As substituições se deram nos teores de $20 \%, 50 \%$ e $100 \%$ em relação a massa seca do cimento. Um peso específico aparente seco de $20 \mathrm{kN} / \mathrm{m}^{3}$ foi adotado bem como um teor de umidade de 7\% para confecção de corpos de prova seguindo a metodologia Marshall. Estes posteriormente foram avaliados quanto a resistência à tração por meio de compressão diametral. A substituição de $20 \%$ se mostrou favorável atendendo as exigências mínimas de utilização estabelecidas pela norma DNIT 167/2013-ES, portanto, podendo representar uma drástica redução no consumo de cimento nestes casos, contribuindo de forma técnica, econômica e ambientalmente.
\end{abstract}

Palavras-chave: Resíduos. Cinza de Casca de Arroz. Resistência à Tração. Materiais Alternativos.

Abstract: Nowadays ordinary Portland cement is one of the most consumed products worldwide. In the same way, it is one of the major responsible for the emission of carbon dioxide $\left(\mathrm{CO}_{2}\right)$ in the atmosphere due to of the way it is produced. There is an urgent necessity to substitute this one or at least to reduce its consumption. The overall trend is one society that starts to consume and reuse its own residue due to your own necessity and to decrease the usage of natural raw materials and, in the same time, consequently by the inevitability of treatment of those that needs a correct disposal. In this way, numerous alternative materials have emerged susceptible to substitution of the conventional ones, such as the Rice Husk Ash result of the burning process of the organic material remaining from the rice husk. In the current work, the partial and total replacement of the cement by Rice Husk Ash is verified, evaluating its potential of use in the paving. The substitutions were conducted in the contents of $20 \%, 50 \%$ and $100 \%$ in relation to the dry mass of the cement. A specific apparent dry weight of $20 \mathrm{kN} / \mathrm{m}^{3}$ was adopted as well as a moisture content of $7 \%$ for the preparation of test specimens following the Marshall methodology. After this the specimens were evaluated by Splitting-Tensile Strength. The substitution of $20 \%$ was favorable considering the minimum requirements of usage determined by DNIT

\footnotetext{
${ }^{1}$ Universidade de Passo Fundo (UPF), Passo Fundo, RS. E-mails: (jupira@upf.br, goldoni@upf.br, brunaazevedo.eng@gmail.com)

2 Universidade Federal do Rio Grande do Sul (UFRGS), Porto Alegre, RS. E-mail: (gustavo.miguel@ufrgs.br)
} 
167/2013-ES, therefore, it can represent a drastic reduction in the consumption of cement in these cases, contributing technically, economically and environmentally.

Keywords: Residues. Rice Husk Ash. Splitting-Tensile Strength. Alternative Materials.

\section{INTRODUÇÃO}

O Manual de Restauração de Pavimentos Asfálticos do DNIT (2006), define como restauração de pavimentos as atividades necessárias para obter novamente condições de segurança e trafegabilidade. O processo de restauração consiste em um conjunto de atividades relacionadas. Parte-se da definição do problema através da coleta de dados, avaliação dos dados e identificação das restrições. Verificando-se a viabilidade técnica e econômica das opções normalmente encontram-se mais de uma solução para a mesma malha viária. "A restauração é mais uma arte que uma ciência" (DNIT, 2016).

Em obras de infraestrutura, normalmente objetiva-se reduzir custos de construção, aproveitar os materiais existentes, preservar a geometria existente, preservar o meio ambiente, economizar energia e diminuir o tempo de obra. Neste contexto, a reciclagem é atualmente a técnica recomendada pelo DNIT para pavimentos flexíveis no Brasil.

De acordo com o manual do DNIT (2006), a reciclagem pode ser feita das seguintes formas: à quente, à frio, a quente in situ e à frio in situ. $O$ produto gerado por cada uma delas tem de apresentar um material final que apresente características técnicas de acordo com a aplicação pretendida, base ou camada de rolamento. Mesmo as tecnologias a frio apresentando normalmente interrupções maiores no tráfego da via, conceitos mais sofisticados podem ser alcançados como o conceito de trem completo, onde o processo integral de reciclagem é realizado em apenas uma passagem. Segundo o manual técnico da Wirtgen (2012), dos processos de reciclagem, a reciclagem a frio in situ permite que além da camada de rolamento, as camadas de base e sub-base possam ser aproveitadas. Todas elas juntas, corrigidas e estabilizadas geram uma base mais rígida para receber camadas de rolamento convencionais. Para este tipo de reciclagem são necessários aditivos estabilizadores, sendo os agentes estabilizadores mais comuns, material asfáltico, cimento ou cal.

Fedrigo (2015) apresenta um histórico das experiências internacionais com restauração de pavimento e adição de cimento Portland desde o ano de 1985 até o ano de 
2009. Assim como as experiências nacionais desde 1998 até o ano de 2013. A partir deste ano pode-se dizer que as situações em que as restaurações com adição de cimento tornaram-se uma opção de sucesso e rotineiramente utilizada.

O cimento apresenta a função de ligante e agregada as partículas do material reciclado, sendo o grau de cimentação responsável pelo ganho de resistência e consequentemente pelo acréscimo de rigidez na mistura (PCA, 2010). Trabalhos como os desenvolvidos por Fedrigo (2015), López (2016), Kleinert (2016) e Consoli et al. (2020a) ressaltam que o teor de umidade é fator determinante para o teor de cimento utilizado, porém, não tão importante quanto o grau e controle da compactação obtido com as misturas. No que diz respeito ao teor de umidade, em materiais reciclados que normalmente utilizam compactação mecânica, a água utilizada na reciclagem de pavimentos flexíveis apresenta duas funções. Ajudar na compactação do material e hidratar o cimento Portland a qual, deve ser limpa e isenta de substâncias nocivas (PCA, 2010; DNIT, 2013).

Relacionado ao teor de material fresado a ser utilizado nas misturas, estudos e manuais recomendam os teores a serem utilizados com valores próximos a $50 \%$, teores superiores testados apresentam um comportamento menos homogêneo, mais suscetíveis a variação de temperatura e carregamento (PCA, 2005; DNIT, 2013; KOLIAS, 1996; DELLABIANCA, 2004). Especificamente Dellabianca (2004) indica que o filme de asfalto que existe entre o agregado e a nata de cimento utilizada, influência do comportamento tensão deformação do material. Huang et al. (2005) apresenta estudos de concretos utilizando material fresado, e ressalta a importância do teor de ligante restante no material reciclado, pois essa película parece controlar o comportamento do fresado do ponto de vista de ductibilidade gerando, normalmente, um concreto menos resistente e menos frágil. $\mathrm{O}$ manual da Austroads (2010) também indica que o ponto mais fraco entre material fresado e reforço com cimento, é a zona de transição que contém ligante remanescente.

Da mesma forma que a utilização de materiais reciclados vem sendo indicada, neste caso, de materiais fresados do próprio pavimento, cada vez mais a engenharia civil busca alternativas às matérias-primas naturais, seja pela incorporação de subprodutos, resíduos, entre outros, visando uma melhor destinação a estes. Como o caso de Favretto et al. (2020) que propôs o emprego do resíduo proveniente do beneficiamento de pedras semipreciosas como preenchimento de geocélulas. Consoli et al. (2020b) em que a partir do emprego de cinzas volantes, resíduo proveniente da queima de combustíveis em termoelétricas, 
buscaram estabilizar um solo residual. Miguel (2020) por sua vez, com a combinação de cal de carbureto e fibras de vidro moídas, o primeiro um resíduo da produção do gás acetileno enquanto que o segundo, o um subproduto da produção de fibras de vidro, buscou estabilizar um solo dispersivo e sulfatado. Além da vantagem da correta destinação e aproveitamento destes materiais, em se tratando de materiais pozolanicos, vem sendo observado que estes auxiliam na melhora das propriedades da zona de transição, isto é, entre nata de cimento e ligante envelhecido.

Portanto, o presente trabalho tem por objetivo avaliar a substituição de cimento Portland por Cinza de Casca de Arroz, sendo esta uma pozolana proveniente da queima da casca do arroz e, com isto, apresentar uma alternativa ao emprego deste resíduo. Além disto, é também realizada a correção granulométrica do fresado empregado por meio da adição do resíduo proveniente do beneficiamento de pedras semipreciosas. Assim sendo, o atual trabalho faz uso de dois resíduos para a criação de um novo material, este com potencial utilização na recuperação de pavimentos. Tudo isto sendo feito a partir da verificação da resistência à tração das misturas elaboradas.

\section{MATERIAIS}

\subsection{Cinza de Casca de Arroz - CCA}

Para este estudo, a Cinza de Casca de Arroz - CCA ou então Sílica de Casca de Arroz - SCA utilizada é da marca Silcca Nobre a qual é comercializada pela empresa Pilecco Nobre Alimentos LTDA que tem como sede o município de Alegrete - RS sendo esta fornecida por meio de sacos de $50 \mathrm{~kg}$. Segundo Marton et al. (2013) os quais utilizaram o mesmo produto, a produção desta se dá por meio de combustão da casca de arroz em leito fluidizado, o que irá resultar na produção de vapor, calor e energia elétrica. O município de Alegrete - RS e região, devido ao grande cultivo da cultura do arroz faz com que se tenha uma elevada produção tanto da matéria prima que posteriormente servirá como alimento, mas também, do resíduo orgânico proveniente do descascamento do mesmo desta forma, como mencionado, possibilitando a geração de energia elétrica. Além disto, Marton et al. (2013) mencionam que o leito fluidizado tem por objetivo manter a temperatura controlada e assim resultar em uma cinza com características predominantemente amorfas 
com baixo teor de carbono e aspecto similar ao do cimento. A Figura 1, a Figura $3 \mathrm{em}$ conjunto com a Tabela 1 apresentam as principais características do produto utilizado.

Figura 1 - Granulometria CCA

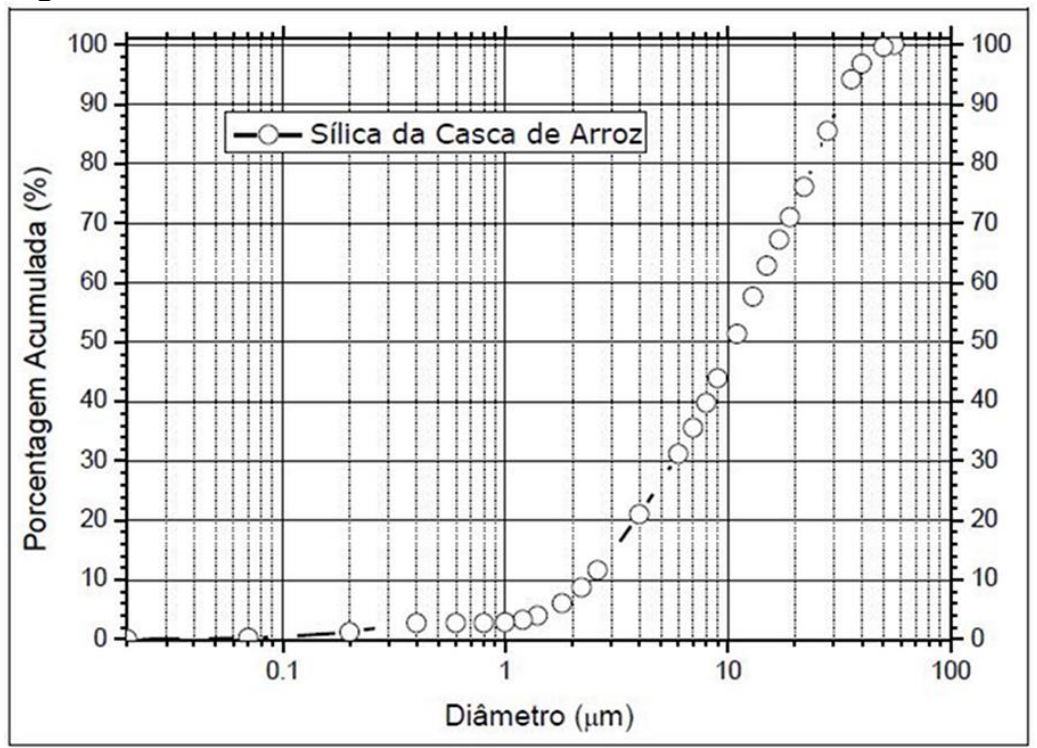

Fonte: Marton et al. (2013)

Figura 2 - Difratograma CCA

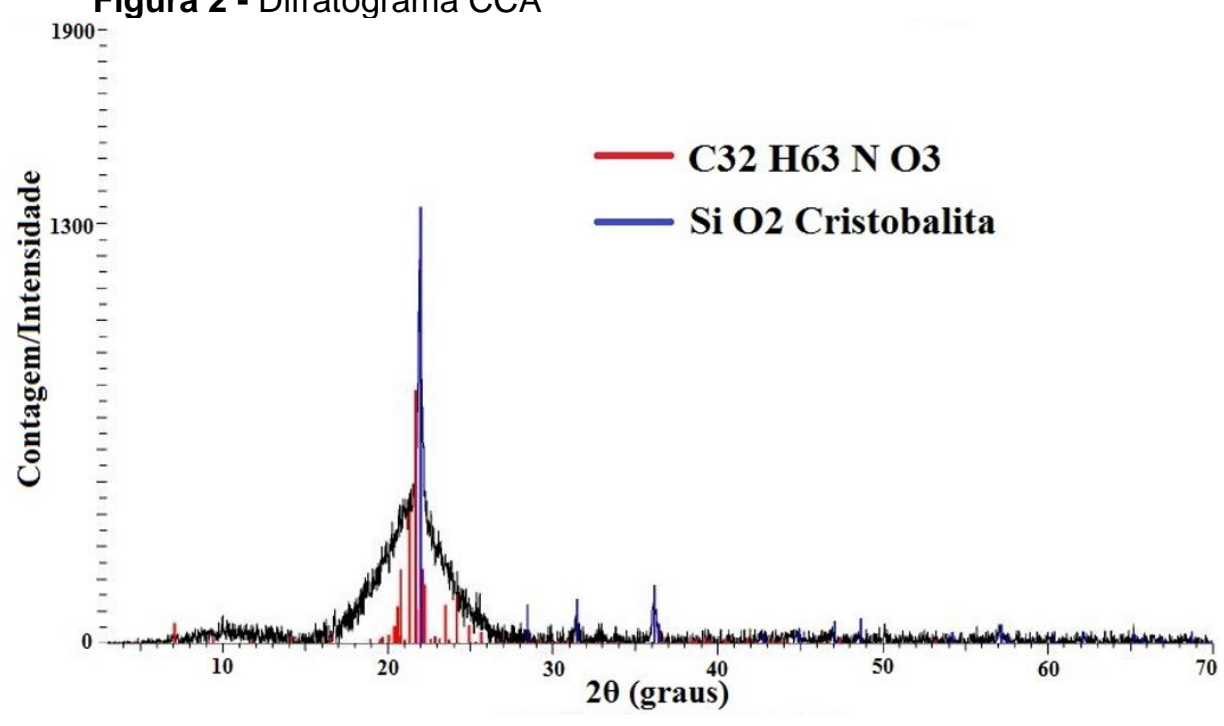

Na Figura 2 é possível observar o difratograma realizado da cinza de casca de arroz, onde alguns picos são verificados. Comportamento este em geral de materiais cristalinos que possam vir a ter desenvolvido cristais durante a confecção do produto já que este por característica deveria ser amorfo. Pires et al. (2016) mencionam que a constatação de picos no difratograma podem representar a queima errada da casca de arroz, ultrapassando os $600^{\circ} \mathrm{C}$ e contribuindo para a cristalização do material. Duart (2008) e Sokolovicz (2013) da mesma forma, mencionam que a queima da casca de arroz a temperaturas muito elevadas 
do que a necessária faz com que ocorra a diminuição da sílica amorfa encontrada no material. A queima em temperaturas erradas pode vir a reduzir o potencial e a qualidade da cinza resultante que posteriormente será empregada em fins diversos.

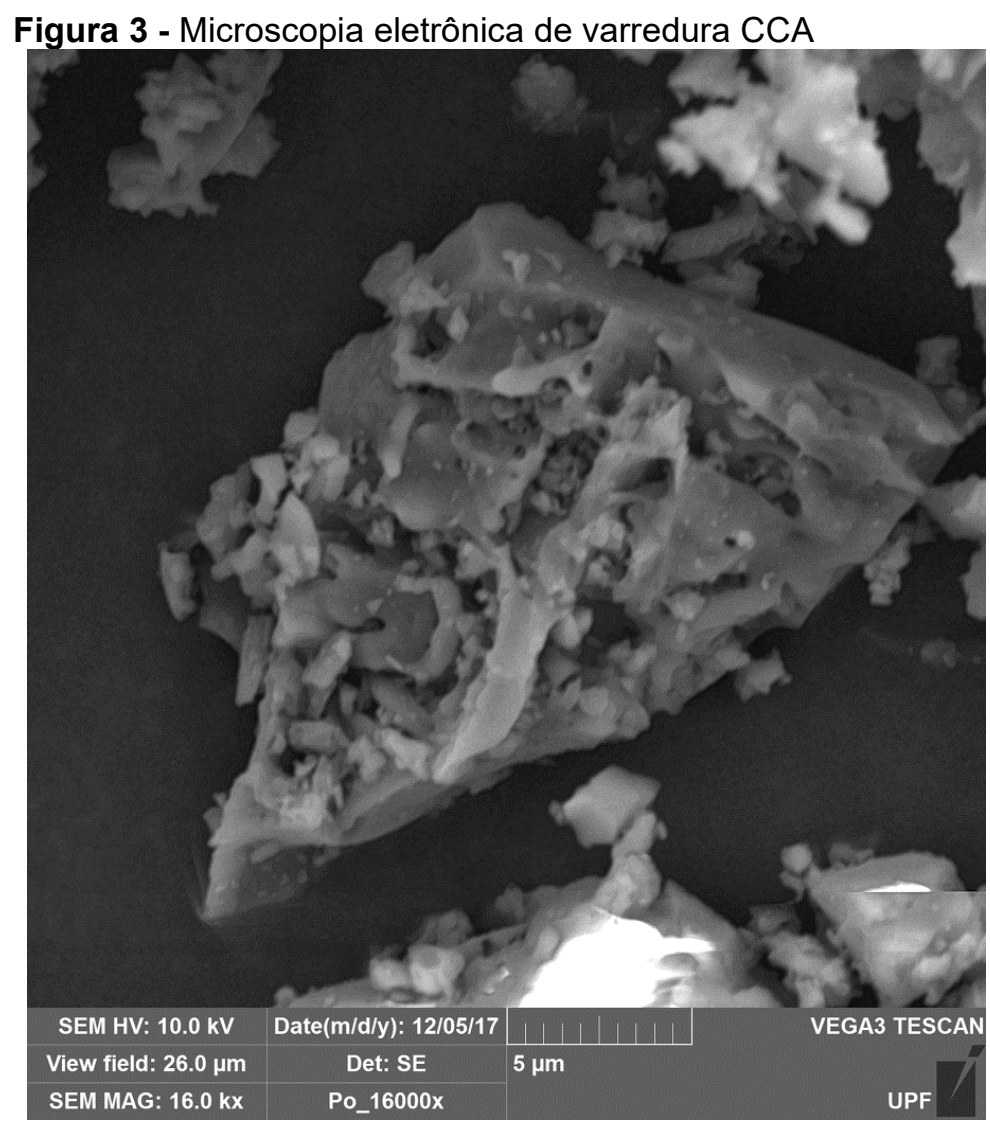

Tabela 1 - Características físico-químicas CCA

\begin{tabular}{cc}
\hline Fórmula & Concentração \\
\hline Dióxido de Silí́io - $\mathrm{SiO}_{2}$ & $91,48 \%$ \\
Óxido de Cálcio - $\mathrm{CaO}$ & $0,36 \%$ \\
Óxido de Magnésio - $\mathrm{MgO}$ & $0,32 \%$ \\
Óxido de Ferro - $\mathrm{Fe}_{2} \mathrm{O}_{3}$ & $0,05 \%$ \\
Óxido de Alumínio - $\mathrm{Al}_{2} \mathrm{O}_{3}$ & $0,00 \%$ \\
Óxido de Sódio - $\mathrm{Na}_{2} \mathrm{O}$ & $0,04 \%$ \\
Óxido de Potássio - $\mathrm{K}_{2} \mathrm{O}$ & $1,40 \%$ \\
Óxido de Manganês - $\mathrm{MnO}$ & $0,32 \%$ \\
Anidrido Sulfúrico - $\mathrm{SO}_{3}$ & $0,15 \%$ \\
Pentóxido de Difósforo - $\mathrm{P}_{2} \mathrm{O}_{5}$ & $0,45 \%$ \\
Área Específica & $21142 \mathrm{~m} / \mathrm{kg}$ \\
Perda ao Fogo & $3,50 \%$ \\
\hline
\end{tabular}




\subsection{Material Fresado da BR-285}

O material utilizado como principal componente da mistura de agregados é resultante da reciclagem profunda de pavimentos, sendo este oriundo da reparação da BR-285 km 241 localizado próximo ao trevo de acesso do município de Ciríaco - RS (FERREIRA, 2016). Material este que até pouco tempo atrás no Brasil, não possuía uma alta estima por parte das empresas responsáveis pela restauração e pavimentação de rodovias onde acabava por ser depositado as margens das mesmas muitas vezes sem levar em consideração os possíveis danos gerados ao meio ambiente. Concepção esta que sofreu grande transformação e atualmente $\mathrm{o}$ material fresado oriundo da reciclagem de pavimentos adquiriu valor agregado passando a ser utilizado na própria restauração do pavimento. Para o caso do material adquirido junto a BR-285 km 241, este possui sua granulometria conforme apresentada na Figura 4.

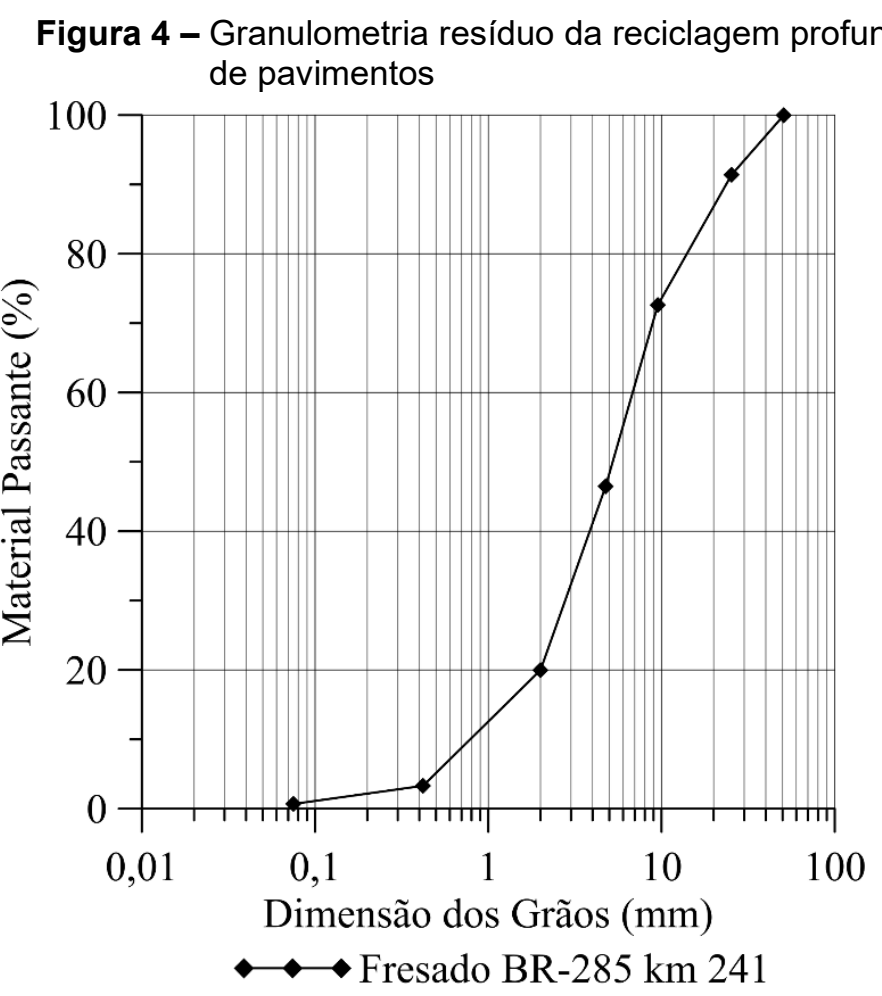




\subsection{Resíduo do Beneficiamento de Pedras Semipreciosas}

O material adotado para estabilização granulométrica do resíduo proveniente da reciclagem profunda de pavimentos é outro resíduo, este resultante do beneficiamento de ágata gerado do rolamento, polimento e lixamento da matéria prima que posteriormente será comercializado como pedras semipreciosas, sua granulometria é apresentada pela Figura 5. Este material é encontrado em polos produtores destes artefatos que, para o caso deste trabalho, foi colhido do município de Soledade, Rio Grande do Sul, distante cerca de $224 \mathrm{~km}$ da capital Porto Alegre. Muitas vezes, estes por estarem mal estocados, acabam trazendo riscos a população e a fauna e flora local por acumularem-se dezenas de toneladas e, em sua grande maioria sem tratamento algum. Riscos de contaminação e assoreamento de riachos são eventos suscetíveis somado a isto, as pilhas de resíduos acabam ocupando um espaço que poderia haver a implementação de uma nova atividade necessitando desta forma, o desenvolvimento de uma metodologia de tratamento que possa dar utilidade a este outro resíduo (MIGUEL; ENDLER; FLOSS, 2017).

Em simultâneo a problemática acima exposta, a escolha do resíduo de ágata como material estabilizante, que pertencente a classe mineral dos silicatos e segundo Tonello (2017) por meio de fluorescência e difração em Raios-X (Figura 6 e Tabela 2) tem como principais elementos em sua composição o dióxido de silício $\left(\mathrm{SiO}_{2}\right)$, uma estrutura predominantemente cristalina e massa específica de $2,48 \mathrm{~g} / \mathrm{cm}^{3}$, tem por objetivo usufruir de características como sua alta dureza onde, conforme a escala de Mohs que varia de 1 a 10 e que se associa ao valor da unidade a substância talco e ao valor da dezena ao diamante (substância mais dura conhecida na natureza), a ágata está classificada com o valor 7 . Além disto, Tonello (2016) após ensaios laboratoriais pode inferir que o resíduo não apresenta qualquer atividade química, permanecendo inerte. Devido as condições de granulometria adequada, elevada dureza e ausência de atividade química espera-se que este resíduo venha ter um ótimo desempenho físico, mas, principalmente químico quando empregado em conjunto com a cinza de casca de arroz. 


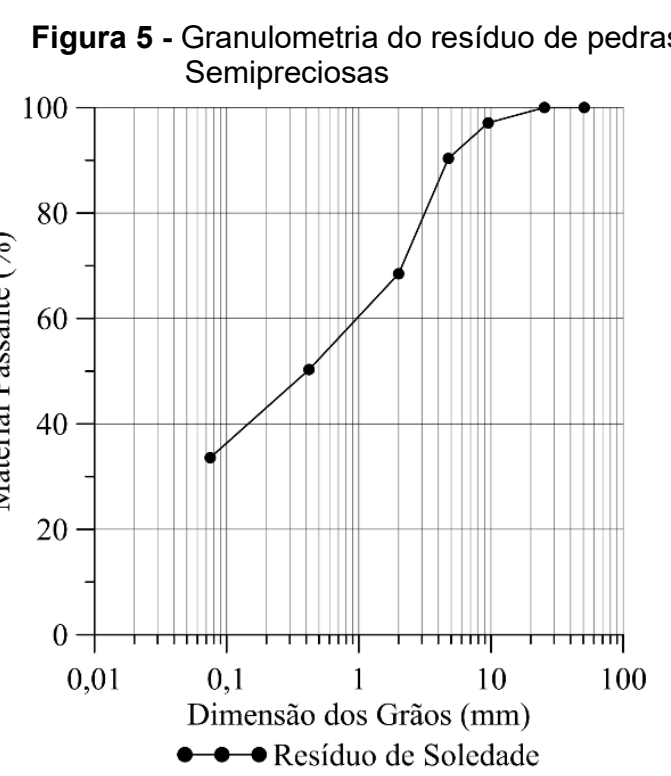

Fonte: Modificado de Baruffi (2017)
Figura 6 - Difratograma do resíduo de pedras semipreciosas

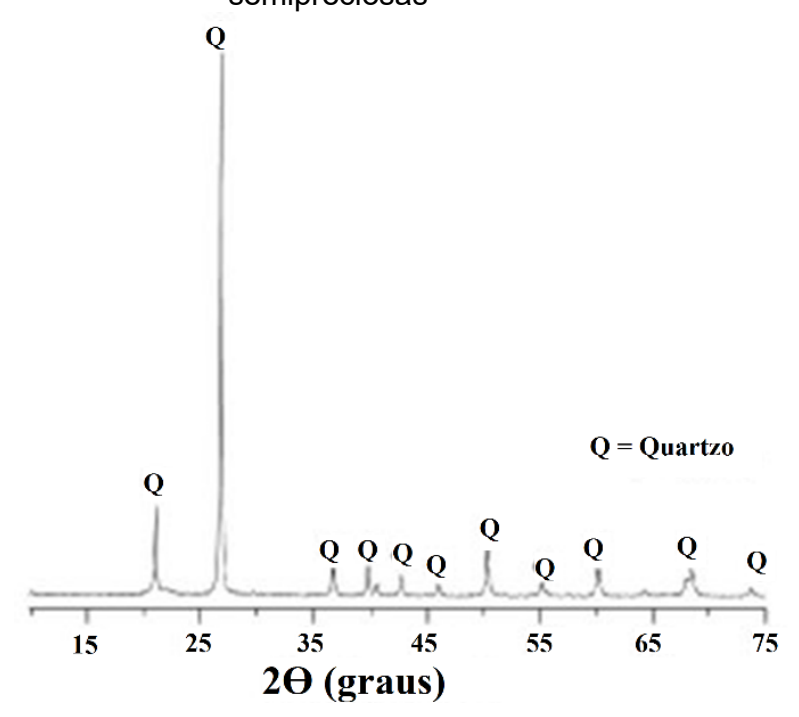

Fonte: Modificado de Tonello et al. (2017)

Tabela 2 - Composição química do resíduo

\begin{tabular}{|c|c|}
\hline Fórmula & Concentração \\
\hline $\mathrm{SiO}_{2}$ & $92,64 \%$ \\
\hline $\mathrm{Al}_{3} \mathrm{O}_{2}$ & $2,24 \%$ \\
\hline $\mathrm{Fe}_{2} \mathrm{O}_{3}$ & $1,45 \%$ \\
\hline $\mathrm{CaO}$ & $1,01 \%$ \\
\hline $\mathrm{P}_{2} \mathrm{O}_{5}$ & $0,89 \%$ \\
\hline $\mathrm{SO}_{3}$ & $0,54 \%$ \\
\hline $\mathrm{Cl}$ & $0,41 \%$ \\
\hline $\mathrm{K}_{2} \mathrm{O}$ & $0,36 \%$ \\
\hline $\mathrm{TiO}_{2}$ & $0,12 \%$ \\
\hline $\mathrm{BaO}$ & $0,10 \%$ \\
\hline $\mathrm{MnO}$ & $0,05 \%$ \\
\hline
\end{tabular}

Fonte: Modificado de Tonello et al. (2017)

\subsection{Cimento Portland}

Levando-se em consideração todo o panorama até então exposto, o qual se alicerça na reutilização de resíduos e tem por objetivo a rápida eliminação destes do meio ambiente, adotou-se como aglomerante o Cimento Portland CP V - Ari Estrutura este capaz de atingir altas resistências já nos primeiros dias de vida além de possibilitar uma redução no consumo quando comparado aos demais devido sua alta eficiência inicial (InterCement, 2012). O cimento utilizado é comercializado pela empresa InterCement que tem como sede 
a cidade de São Paulo - SP sendo esta fornecida por meio de sacos de $40 \mathrm{~kg}$. Algumas de suas características são apresentadas pela Tabela 3.

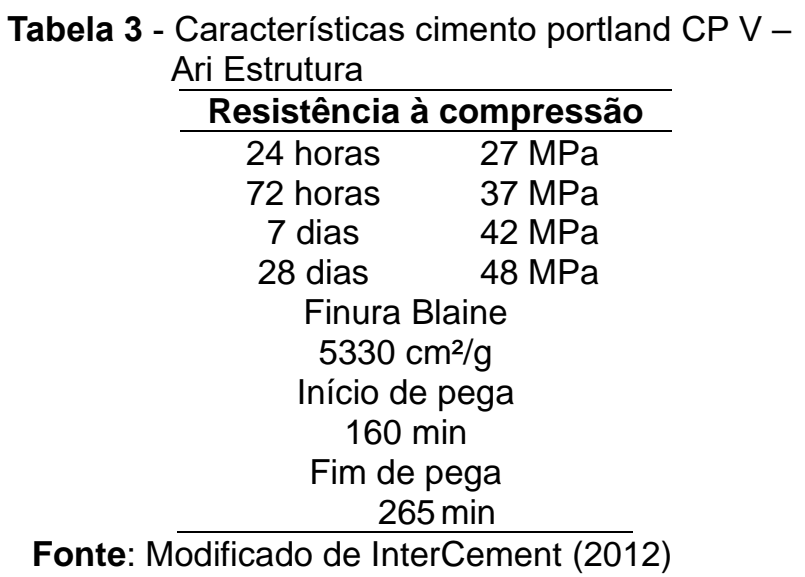

\section{MÉTODOS}

O presente trabalho como já mencionado, que tem por objetivo avaliar a substituição de Cimento Portland por CCA a partir da verificação da resistência à tração de uma mistura de resíduos possibilitando assim sua aplicação a pavimentação ou não, fundamenta-se principalmente nas seguintes normas DNIT 167/2013-ES, DNIT 136/2017-ME e DNER-ME 043/95. Em um primeiro momento, após a verificação granulométrica e de demais características dos resíduos, buscou-se adequar estes ao atendimento das normas anteriormente mencionadas para isto, no caso do material adquirido na BR-285 km 241, este após a coleta em campo, teve sua estocagem e secagem ao ar livre sendo tomados os cuidados para homogeneização e quarteamento das amostras em cada processo de utilização deste resíduo.

Levando-se em consideração a adequação granulométrica exigida pela norma DNIT 167/2013-ES, tanto para o caso do resíduo oriundo da fresagem do pavimento quanto para o proveniente do beneficiamento de pedras semipreciosas, ambos necessitaram ajustes prévios. A referida norma estabelece duas possibilidades de enquadramento de faixas granulométricas, Faixa I e Faixa II, sendo que a primeira estabelece pré-requisito de que no máximo $90 \%$ do material deve ser passante pela peneira de abertura de $25 \mathrm{~mm}$ (1") caso este que não ocorre já que cerca de $91,4 \%$ do material fresado passa pela peneira mencionada, já para o caso da segunda faixa, esta possui como pré-enquadramento que $100 \%$ do material fresado passe pela peneira de abertura de $25 \mathrm{~mm}$ possibilidade esta que 
pode ser empregada ao material com tratamento prévio e descarte dos possíveis agregados que vieram a ficar retidos nesta peneira. Desta forma, como tratamento prévio, adotou-se como granulometria a ser atendia àquela exigida pela Faixa II onde trabalhou-se com o material passante na peneira de abertura de $25 \mathrm{~mm}$ (1") e retido na peneira de abertura $0,075 \mathrm{~mm}\left(\mathrm{n}^{\circ} .200\right)$.

Além disto, o enquadramento aos requisitos da Faixa II demandou uma estabilização granulométrica do resíduo oriundo da fresagem de pavimentos, motivo este que conforme já mencionado justifica a utilização do resíduo proveniente do beneficiamento de pedras semipreciosas que tem unicamente como objetivo principal fazer com que ocorra o enquadramento à faixa adotada. Neste caso, a dosagem dos materiais baseou-se no Método das Tentativas comumente utilizado na área de pavimentação, onde a adequação à faixa adotada se deu por meio da utilização de $70 \%$ de material fresado e $30 \%$ de material oriundo do beneficiamento de pedras semipreciosas, mesma dosagem encontrado por Ferreira (2016) onde se tratavam dos mesmos materiais. A Figura 7 exibe a estabilização granulométrica com a adequação aos limites da faixa.

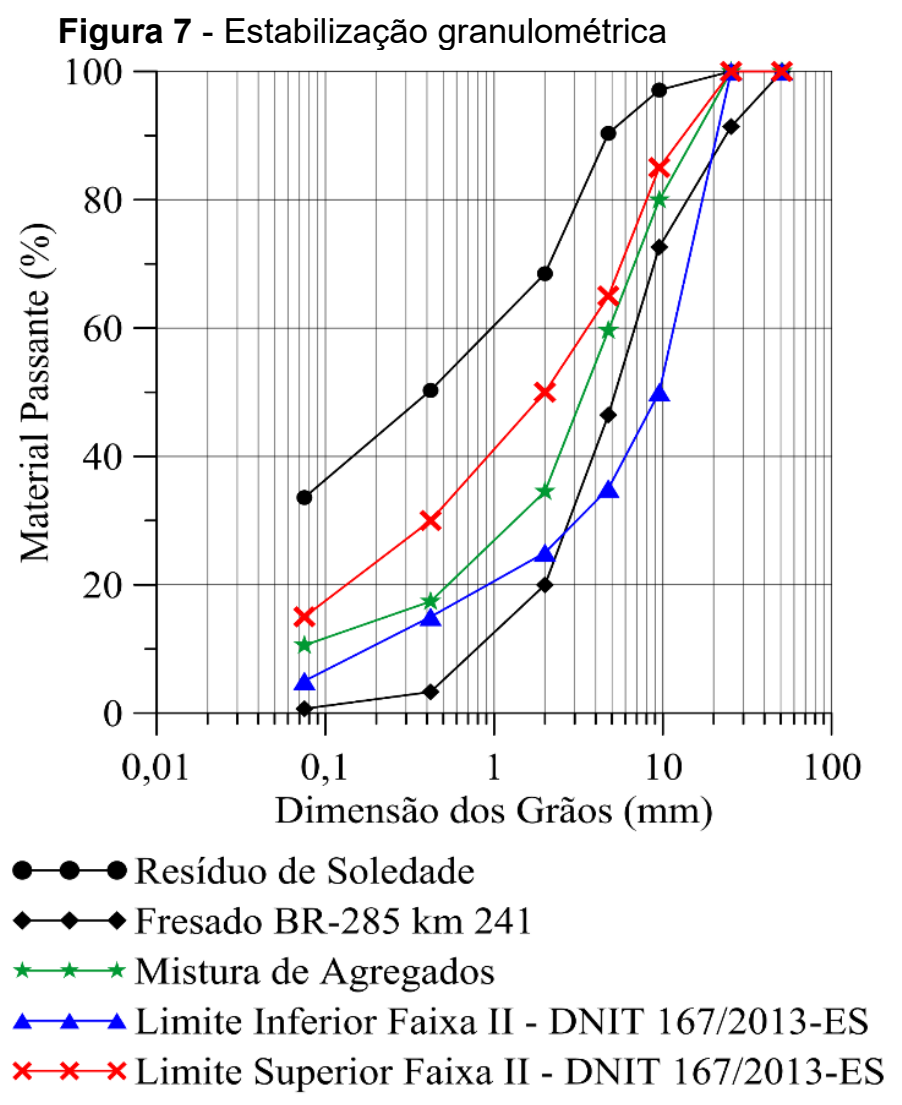


A norma DNIT 167/2013-ES recomenda que para um bom comportamento da mistura reciclada, a participação do resíduo proveniente da reciclagem profunda de pavimentos se limite a 50\% em massa, em relação a massa seca da mistura. Circunstância que não ocorre neste caso, onde estão sendo utilizados $70 \%$ anteriormente mencionados, porém, acredita-se que este limitador estabelecido deve-se muito as incertezas que circundam um resíduo onde muitas vezes pode haver uma grande variação em termos de suas características fazendo com que agregados naturais pareçam ser de melhor qualidade ou de maior confiança, de fato é uma consideração realmente importante com intuito de se garantir uma boa qualidade do pavimento, no entanto, o que se busca neste trabalho é realmente fazer com que se reprima a utilização de matéria-prima natural a qual encontrase cada vez mais em escassez. Além disto, a mistura utilizada atendendo aos requisitos mínimos exigidos em norma não necessariamente tenha de ser utilizada como pista de rolamento, podendo ser empregada em demais camadas do pavimento. Desta forma, manteve-se a dosagem de $70 \%$ material fresado e $30 \%$ material do beneficiamento de pedras semipreciosas.

A metodologia de ensaio consistiu na confecção de corpos de prova cilíndricos seguindo as recomendações estabelecidas na norma DNER-ME 043/95 através da utilização da aparelhagem Marshall. Desta forma, corpos de prova contendo aproximadamente 101,5 mm de diâmetro e $63,5 \mathrm{~mm}$ de altura foram confeccionados (Figura 8). Para isto, um único peso específico aparente seco foi considerado com valor de 20 $\mathrm{kN} / \mathrm{m}^{3}$, este com o intuito de se obter uma única densidade. Também, para o momento da moldagem dos corpos de prova, água de abastecimento público foi utilizada esta na porcentagem de $7 \%$ em relação a massa seca, com base nos estudos prévios já realizados por Ferreira (2016). 
Figura 8 - Confecção dos corpos de prova cilíndricos: a) materiais utilizados; b) corpos de prova e mistura dos materiais

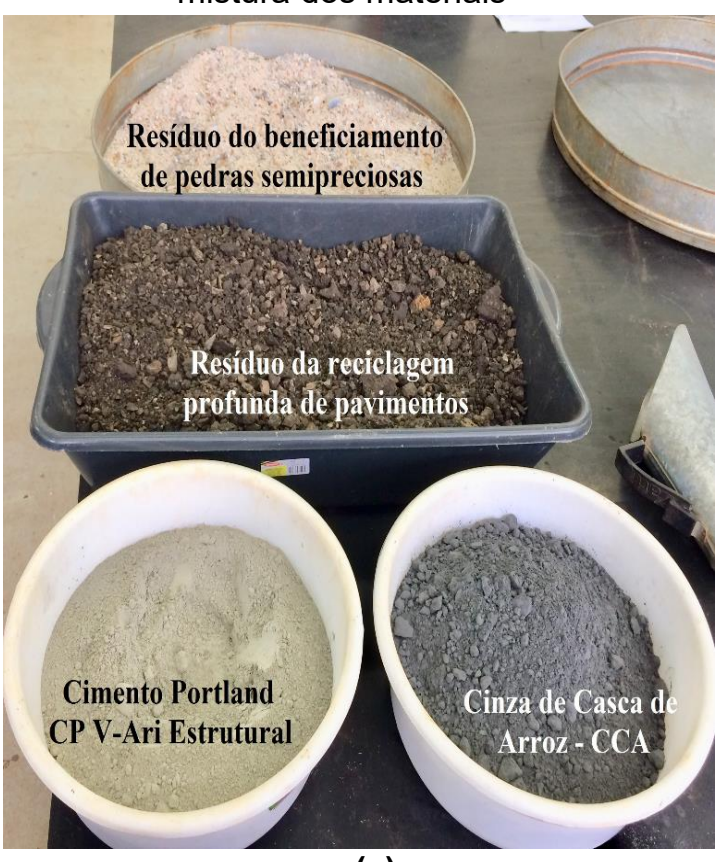

(a)

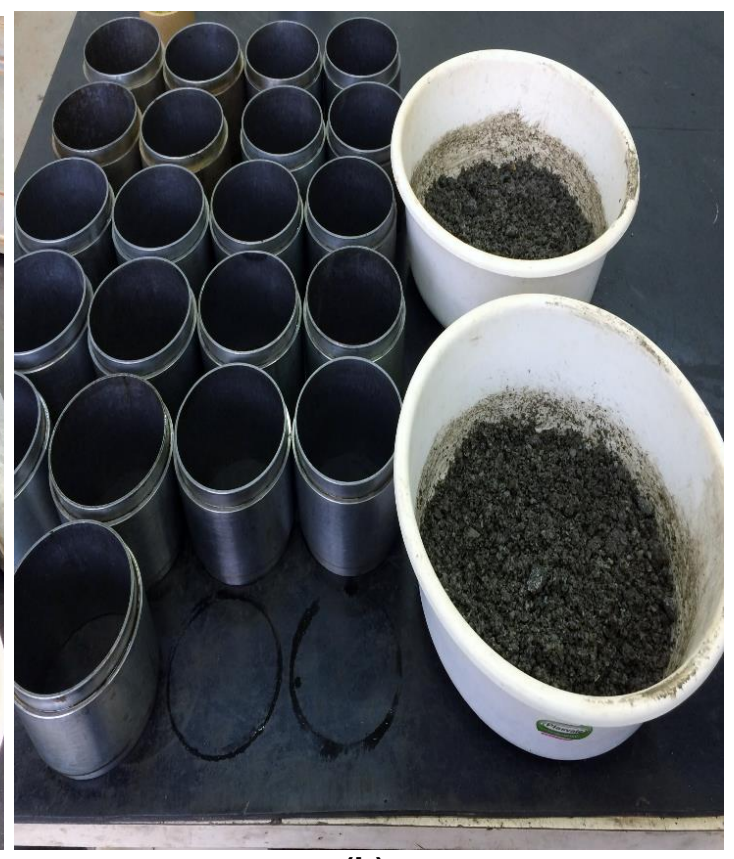

(b)

Para a verificação da resistência à tração 24 corpos de prova foram moldados sendo que destes, 6 foram tomados como referência os quais possuíam adição integral de cimento sem qualquer substituição sendo esta adição de cimento determinada pelo teor ótimo de $3,63 \%$ da mistura reciclada seca, este teor ótimo foi determinado por Ferreira (2016) e utilizado para este trabalho por se tratarem dos mesmos materiais que compõem a mistura. Já os demais, dividiram-se em uma substituição do cimento por cinza de casca de arroz nas seguintes proporções $20 \%, 50 \%$ e 100\% todas estas em relação a massa seca do cimento. Desta forma, este estudo possui 4 traços onde cada uma destes possui 6 corpos de prova totalizando o que anteriormente foi mencionado, a Tabela 4 apresenta de forma resumida o que aqui foi mencionado. A intenção da moldagem de seis corpos de prova por traço tem por objetivo realizar o rompimento destes, tanto aos 7 dias de cura quanto aos 21 dias. A determinação da resistência à tração se deu por meio da compressão diametral dos corpos de prova e teve como base a norma DNIT 136/2017-ME, a seguir são apresentados os resultados e conclusões obtidas. 
Tabela 4 - Resumo da variação de ensaios

\begin{tabular}{ccccccc}
\hline Traços das misturas & $\begin{array}{c}\text { Teor de } \\
\text { Umidade }\end{array}$ & $\begin{array}{c}\text { Resíduo de } \\
\text { reciclagem } \\
\text { profunda de } \\
\text { pavimentos }\end{array}$ & $\begin{array}{c}\text { Resíduo do } \\
\text { beneficiamento de } \\
\text { pedras } \\
\text { semipreciosas }\end{array}$ & $\begin{array}{c}\text { Cimento } \\
\text { Portland } \\
\text { CP V-Ari }\end{array}$ & $\begin{array}{c}\text { Cinza de } \\
\text { Casca de } \\
\text { Arroz - CCA }\end{array}$ & $\begin{array}{c}\text { Número } \\
\text { de corpos } \\
\text { de prova }\end{array}$ \\
\hline $\begin{array}{c}\text { Referência - 100C/0CCA } \\
\text { Substituição 1 - }\end{array}$ & $7 \%$ & $70 \%$ & $30 \%$ & $100 \%$ & $0 \%$ & 6 \\
$\begin{array}{r}\text { 80C/20CCA } \\
\text { Substituição 2 - }\end{array} \quad 7 \%$ & $70 \%$ & $30 \%$ & $80 \%$ & $20 \%$ & 6 \\
$\begin{array}{c}\text { 50C/50CCA } \\
\text { Substituição 3 - }\end{array}$ & $7 \%$ & $70 \%$ & $30 \%$ & $50 \%$ & $50 \%$ & 6 \\
0C/100CCA & $7 \%$ & $70 \%$ & $30 \%$ & $0 \%$ & $100 \%$ & 6 \\
\hline
\end{tabular}

\section{RESULTADOS}

Os resultados obtidos basearam-se exclusivamente na determinação da resistência à tração por meio da compressão diametral, sendo que a análise destes levou em consideração os requisitos mínimos exigidos pela norma DNIT 167/2013-ES a qual estabelece uma faixa que varia de $0,25 \mathrm{MPa}$ a $0,35 \mathrm{MPa}$ de resistência à tração aos sete dias de cura. Portanto, em um primeiro momento, a avaliação realizada leva em conta os requisitos mínimos exigidos pela referida norma ao atendimento destes ou não, para isto a Tabela 5 e a Figura 9 apresentam os resultados encontrados.

Tabela 5 - Resultados obtidos

\begin{tabular}{ccccc}
\hline $\begin{array}{c}\text { Tempo } \\
\text { de cura }\end{array}$ & $\begin{array}{c}\text { Cimento } \\
\text { Portland }\end{array}$ & $\begin{array}{c}\text { Cimento } \\
\text { Portland na } \\
\text { mistura }\end{array}$ & CCA & RTCD \\
\hline 7 dias & $100 \%$ & $3,63 \%$ & $0 \%$ & $0,32 \mathrm{MPa}$ \\
7 dias & $80 \%$ & $2,90 \%$ & $20 \%$ & $0,28 \mathrm{MPa}$ \\
7 dias & $50 \%$ & $1,82 \%$ & $50 \%$ & $0,18 \mathrm{MPa}$ \\
7 dias & $0 \%$ & $0,00 \%$ & $100 \%$ & $0,01 \mathrm{MPa}$ \\
21 dias & $100 \%$ & $3,63 \%$ & $0 \%$ & $0,45 \mathrm{MPa}$ \\
21 dias & $80 \%$ & $2,90 \%$ & $20 \%$ & $0,44 \mathrm{MPa}$ \\
21 dias & $50 \%$ & $1,82 \%$ & $50 \%$ & $0,27 \mathrm{MPa}$ \\
21 dias & $0 \%$ & $0,00 \%$ & $100 \%$ & $0,02 \mathrm{MPa}$ \\
\hline
\end{tabular}


Figura 9 - Variação da resistência à tração para diferentes substituições de CCA

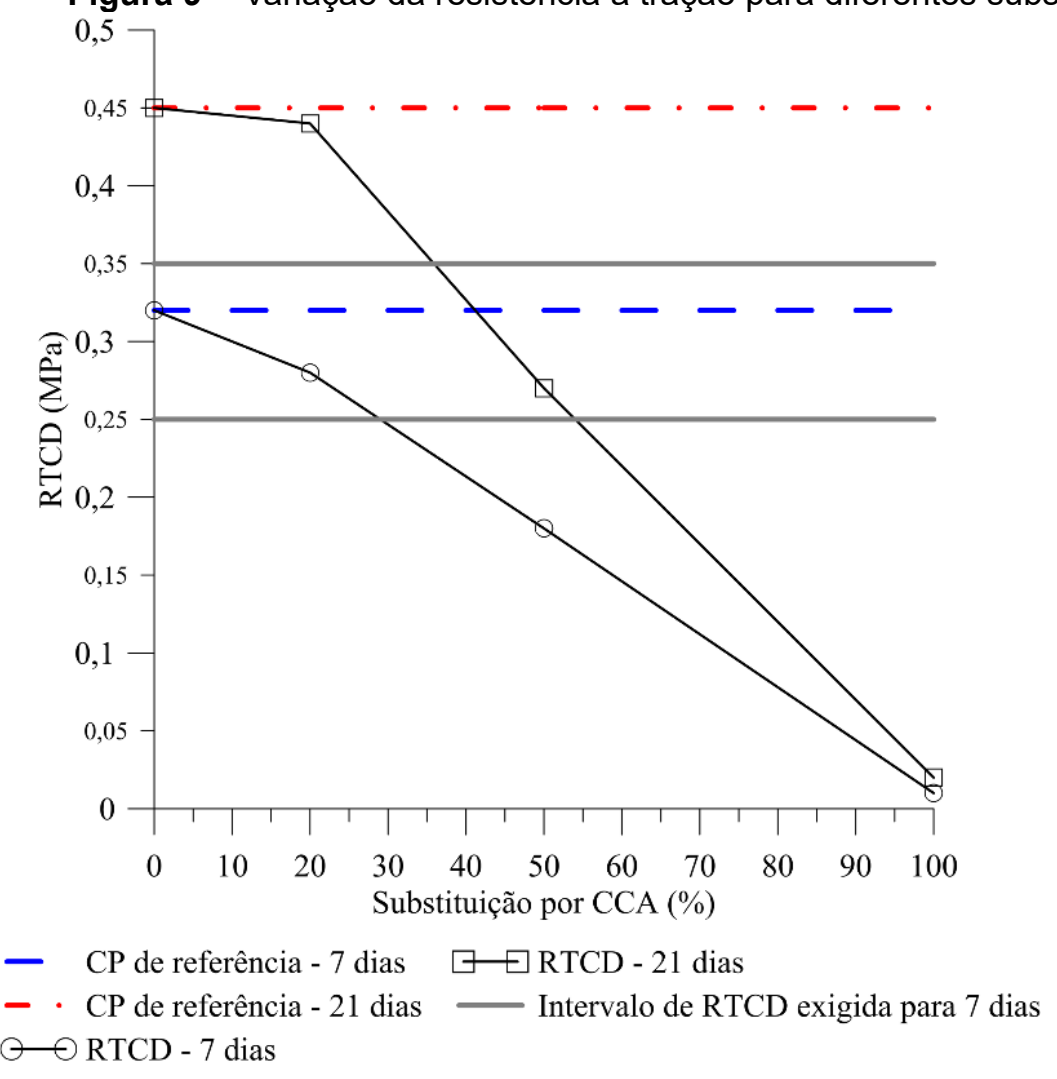

Levando em consideração o que até então foi estabelecido, apenas dois dos quatro traços atendem aos requisitos mínimos de resistência à tração para os sete dias de cura como pode ser observado na Figura 9, que são os casos dos corpos de prova os quais utilizaram 0\% de CCA como substituição (corpo de prova de referência para os sete dias de cura) e, $20 \%$ de CCA como substituição ao cimento Portland em relação a sua massa seca. As demais substituições se mostraram desfavoráveis resultando em uma queda vertiginosa da resistência à tração conforme a adição de altos teores de CCA.

Desta forma, para o atendimento à norma DNIT 167/2013-ES substituições de cimento Portland por CCA acima de $20 \%$ não demonstraram ser favoráveis levando-se em consideração a resistência à tração. No entanto, quando observado as resistências àquelas obtidas para 21 dias de cura, três traços passam a atender ou superar os requisitos mínimos estabelecidos em norma, onde as substituições por 50\% de CCA vem a atingir a faixa de resistência pré-estabelecida. Por mais que a norma considerada como referência não aborde a alternativa de 21 dias de cura é bastante significativa a possibilidade de substituir metade do cimento Portland por um material alternativo a este, por isto uma melhor avaliação cabe ser realizada quando empregada altas substituições de cimento Portland por CCA em longos períodos de cura visto que a adição de uma pozolana que o caso da 
cinza de casca de arroz, esta tem por características apresentar ganho da resistência com o passar do tempo em virtude das reações químicas ali desenvolvidas.

Levando em consideração até então unicamente ao atendimento a norma DNIT 167/2013-ES, o fato de poder reduzir em $20 \%$ o consumo de cimento e mesmo assim mantendo-se ao atendimento desta, demostra uma possibilidade benéfica ao meio ambiente onde pode representar uma queda bastante significativa da emissão de dióxido de carbono na atmosfera além disto, a redução do consumo de cimento vem a tornar a mistura mais econômica.

Figura 10 - Microscopia eletrônica de varredura misturas: a) 100C/0CCA; b) 80C/20CCA; c) 50C/50CCA e, d) $0 \mathrm{C} / 100 \mathrm{CCA}$

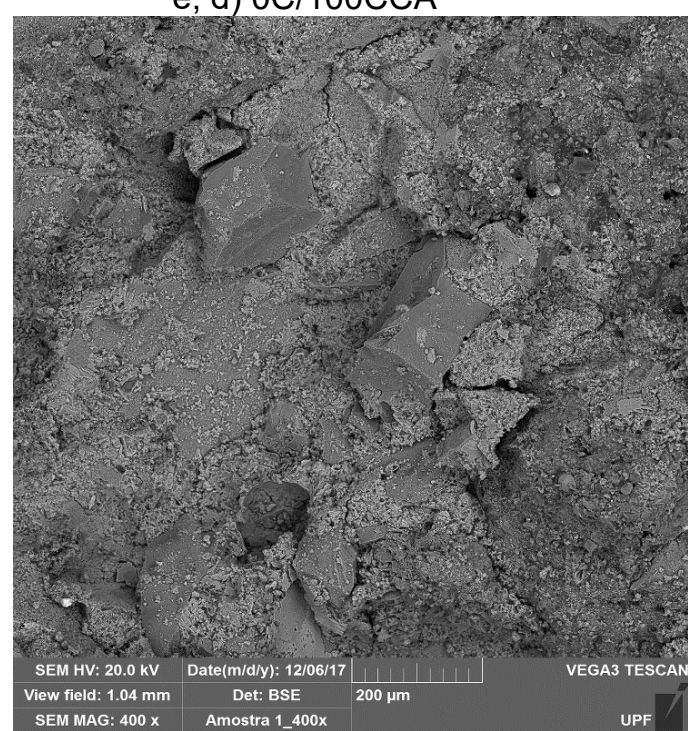

(a)

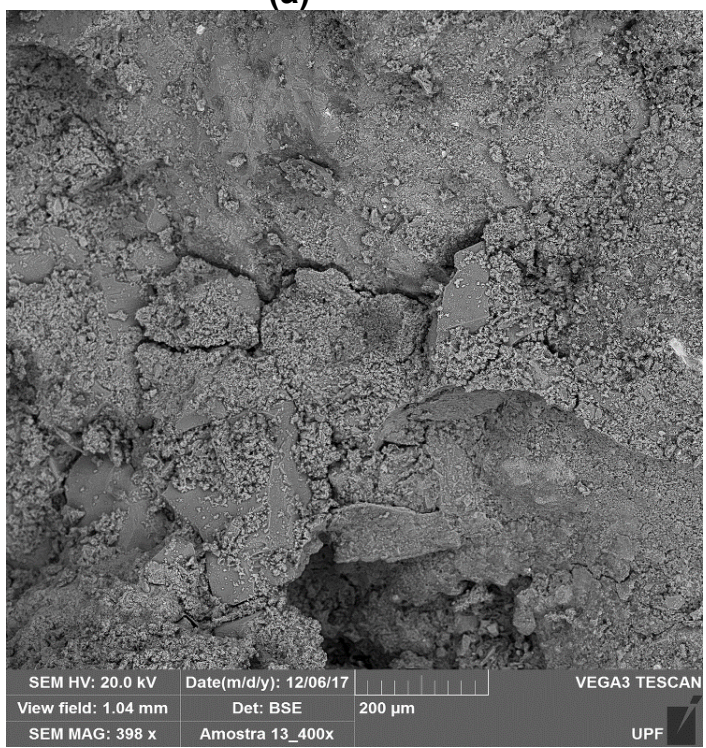

(c)

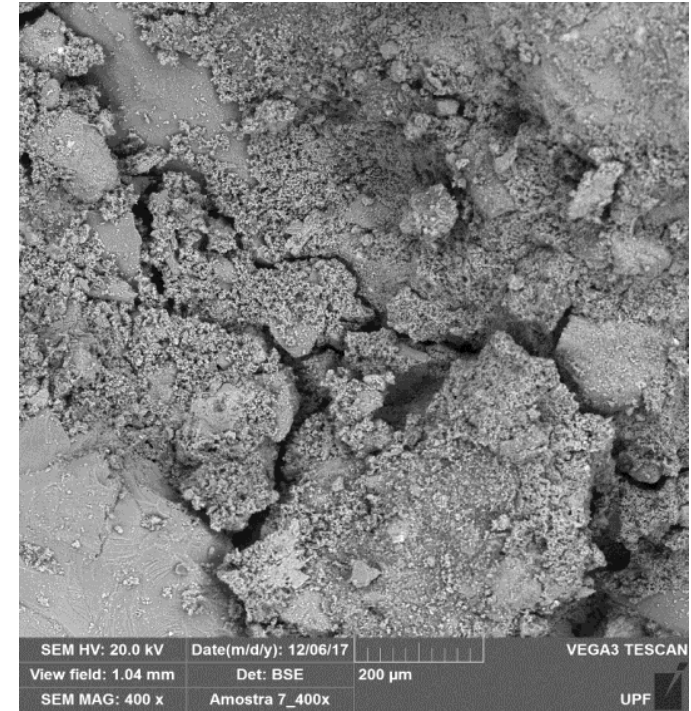

(b)

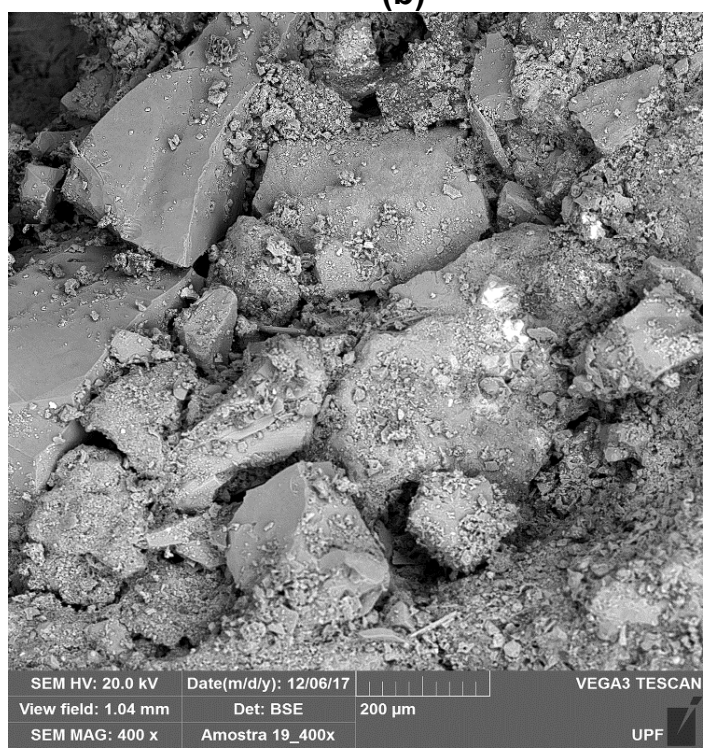

(d) 
As imagens obtidas por microscopia eletrônica de varredura vêm auxiliar de forma qualitativa o que já é apresentado pela Figura 9 onde, quando comparadas as imagens que compõem a Figura 10, é possível observar uma redução da cimentação do material conforme é aumentado a adição de CCA, consequentemente, como no caso da Figura 10d, um maior número de vazios é notado devido ao alto teor de CCA o que vem a justificar sua baixa resistência e não atendimento a norma DNIT 167/2013-ES.

\section{CONCLUSÕES}

As conclusões a seguir tratam-se de breves observações do comportamento à tração de uma mistura quando da substituição de um de seus componentes por cinza de casca de arroz em teores variados, para uma maior compreensão de seu desempenho, testes complementares são recomendados.

1) As substituições de altos teores de cimento Portland por cinza de casca de arroz não apresentaram um desempenho satisfatório, ao passo em que quanto maior a adição de cinza de casca de arroz pior é o desempenho à tração;

2) Do ponto de vista técnico, econômico e ambiental, a substituição de $20 \%$ de cimento Portland por cinza de casca de arroz foi o único traço a atender todos estes requisitos. Capaz de atender as exigências mínimas de resistência estabelecidas pela norma DNIT 167/2013-ES além de possibilitar uma redução de custos e um benefício ao meio ambiente em virtude da redução da utilização de cimento Portland;

3) Maiores substituições de cimento Portland por cinza de casca de arroz, como o caso de $50 \%$ de substituição, vieram apresentar desempenho satisfatório apenas com o passar do tempo já com 21 dias de cura.

\section{REFERÊNCIAS}

ASSOCIATION OF AUSTRALASIAN ROAD TRANSPORT AND TRAFFIC AGENCIES . Cost effective structural treatments for rural highways: cemented materials. Austroads Publication AP -T168. Sydney, 188p. 2010.

BARUFFI, A. Comportamento mecânico de geocélulas preenchidas com resíduos de pedras preciosas. 2017. Dissertação (Mestrado em Engenharia) - Programa de Pós-Graduação em Engenharia Civil e Ambiental, Universidade de Passo Fundo, RS, p. 95, 2017. 
CONSOLI, N. C.; MOREIRA, E. B.; FESTUGATO, L.; MIGUEL, G. D. Spread Footings Bearing on Circular and Square Cement-Stabilized Sand Layers Above Weakly Bonded Residual Soil. Soils \& Rocks, 2020a.

CONSOLI, N. C.; FESTUGATO, L.; SCHEUERMANN FILHO, H. C.; MIGUEL, G.

D.; TEBECHRANI NETO, A.; ANDREGHETTO, D. Durability Assessment of Soil-Pozzolan-Lime Blends through Ultrasonic-Pulse Velocity Test. Journal of Materials in Civil Engineering, v. 32, p. 04020223, 2020b. https://doi.org/10.1061/(ASCE)MT.1943-5533.0003298

DEPARTAMENTO NACIONAL DE ESTRADAS DE RODAGEM. DNER-ME 043/95: misturas betuminosas a quente - ensaio Marshall. Instituto de Pesquisas Rodoviárias (IPR). Rio de Janeiro, 1995.

DEPARTAMENTO NACIONAL DE INFRAESTRUTURA DE TRANSPORTES. DNIT 167/2013-ES: Pavimentação - Reciclagem profunda de pavimentos "in situ" com adição de cimento Portland Especificação de Serviço. Instituto de Pesquisas Rodoviárias (IPR). Rio de Janeiro, 2013.

DEPARTAMENTO NACIONAL DE INFRAESTRUTURA DE TRANSPORTES. DNIT 136/2017-ME: Pavimentação asfáltica - Misturas asfálticas - Determinação da resistência à tração por compressão diametral - Método de Ensaio. Instituto de Pesquisas Rodoviárias (IPR). Rio de Janeiro, 2017.

DEPARTAMENTO NACIONAL DE INFRAESTRUTURA DE TRANSPORTES. DNIT - IPR - 720: Manual de restauração de pavimentos asfálticos. Instituto de Pesquisas Rodoviárias (IPR). Rio de Janeiro, p. 313, 2006.

DELLABIANCA, L. M. A. Estudo do comportamento de material fresado em revestimento asfáltico visando sua aplicação em reciclagem de pavimentos. Tese de Doutorado (Geotecnia) - Departamento de Engenharia Civil e Ambiental, Universidade de Brasília, DF, p. 110, 2004.

DUART, M. A. Estudo da microestrutura do concreto com adição de cinza de casca de arroz residual sem beneficiamento. Dissertação (Mestrado em Engenharia) - Programa de PósGraduação em Engenharia Civil, Universidade Federal de Santa Maria, RS, p. 134, 2008.

FAVRETTO, J.; MIGUEL, G. D.; DONATO, M.; FLOSS, M. F. Circular footing on geocell-reinforced granular residue from precious gem processing over a sand bed. Soils \& Rocks, v. 43, p. 151158, 2020. https://doi.org/10.28927/SR.431151

FERREIRA, M. de C. Comportamento de material de reciclagem profunda de pavimento estabilizado com nata de cimento. Dissertação (Mestrado em Engenharia) - Programa de PósGraduação em Engenharia Civil e Ambiental, Universidade de Passo Fundo, RS, p. 107, 2016.

FEDRIGO, W. Reciclagem de pavimentos com adição de cimento portland: definição das bases para um método de dosagem. Dissertação (Mestrado em Engenharia Civil). Programa de Pós-Graduação em Engenharia Civil, Universidade Federal do Rio Grande do Sul. RS, p. 162, 2015.

HUANG, B; SHU, X; LI, G. Laboratory Investigation of Portland Cement Concrete Containing Recycled Asphalt Pavements. Cement and Concrete Research, v. 35, n. 10, p. 2008 - 2013, 2005. https://doi.org/10.1016/j.cemconres.2005.05.002 
CATÁLOGO CP V - Ari Estrutura. Desenvolvido por InterCement. Disponível em:

http://www.intercement.com/files/pdf/portugues-br/cpv-ari-estrutura.pdf. Acesso em: dez. 2017.

KLEINERT, T. Reciclagem de pavimentos semirrígidos com adição de cimento: contribuição ao desenvolvimento de uma metodologia de dosagem. Dissertação (Mestrado em Engenharia Civil) - Programa de Pós-Graduação em Engenharia Civil, Universidade Federal do Rio Grande do Sul, RS, p. 177, 2016.

KOLIAS, S. The influence of type loading and temperature on the modulus of elasticity of cementbound mixes of milled bituminous concrete and crushed aggregates. Materials and structures, v. 29, p. 543 - 551, 1996. https://doi.org/10.1007/bf02485954

MARTON, L. F. M.; OLIVEIRA, M. D.; MARANGNON, E.; ROSADO, D.; PADOIN, D. G.; MARTINS, R. Avaliação da utilização em pisos intertravados da sílica de casca de arroz obtida através da combustão em leito fluidizado. In: CONGRESSO BRASILEIRO DO CONCRETO, 55. 2013. Gramado, Rio Grande do Sul, Brasil. Proceedings [...]. 2013.

MENDES, G. G.; MARTINS, R. P.; SOARES, E. L.; MARANGON, E.; OLIVEIRA, M. J. D. Durabilidade de concretos com adição de sílica da casca de arroz obtida em leito fluidizado à penetração de íons cloretos. In: CONGRESSO LUSO-BRASILEIRO DE MATERIAIS DE CONSTRUÇÃO SUSTENTÁVEIS. 1., 2014. Guimarães, Portugal. Proceedings [...]. 2014, p. 1-11.

MIGUEL, G. D.; ENDLER, R. R.; FLOSS, M. F. Um estudo da mínima razão de cobrimento adequada a proteger geocompostos argilosos. Revista de Ciências Exatas Aplicadas e Tecnológicas da Universidade de Passo Fundo - CIATEC-UPF, v. 9, n. 2, p. 1-15, 2017. https://doi.org/10.5335/ciatec.v9i2.6442

MIGUEL, G. D. Desempenho e Comportamento Mecânico de Um Solo Dispersivo e Sulfatado Tratado com uma Pozolana Artificial, Cal de Carbureto e Reforçado com Fibras de Vidro.

Dissertação (Mestrado em Engenharia - Geotecnia) - Programa de Pós-Graduação em Engenharia Civil, Universidade Federal do Rio Grande do Sul, RS, p. 281, 2020.

https://doi.org/10.13140/RG.2.2.27481.67687/1

PIRES, G. M.; SPECHT, L. P.; PINHEIRO, R. J. B.; PEREIRA, D. S.; RENZ, E. M. Comportamento mecânico de material fresado após processo de estabilização granulométrica e química por meio da incorporação de cimento e cinza de casca de arroz moída. Revista Matéria, v. 21, n. 02, p. 365-384, 2016. https://doi.org/10.1590/S1517-707620160002.0035

PORTLAND CEMENT ASSOCIATION. Guide to Full Depth Reclamation (FDR) with Cement. Illinois, E.U.A., 2005.

SOKOLOVICZ, B. C. Microestrutura e durabilidade a cloretos de protótipos de concreto com cinza de casca de arroz com e sem moagem prévia. Dissertação (Mestrado em Engenharia) Programa de Pós-Graduação em Engenharia Civil, Universidade Federal de Santa Maria, RS, p. 165, 2013.

TONELLO, R. D.; GOLDONI, A. G.; ROSA, F. D.; DONATO, M.; ARTUSI, R. Use of alternative waste the scroll of semiprecious stone as aggregate in pavers. In: CRICTE - CONGRESSO REGIONAL DE INICIAÇÃO CIENTÍFICA E TECNOLÓGICA EM ENGENHARIA, Joinville, Santa Catarina, Brasil. Proceedings [...]. Bauru: Editora Canal6, 2016, p. 1-4.

TONELLO, R. D., ARTUSI R., GOLDONI, A. G., DALLA ROSA, F., DONATO, M. Pavimento intertravado de concreto produzido com resíduo da rolagem da pedra ágata como substituinte 
parcial do ligante. In: REUNIÃO DE PAVIMENTAÇÃO URBANA - 20 RPU, 2., 2017. Florianópolis, Santa Catarina, Brasil. Proceedings [...]. v.1, 2017.

WIRTGEN GROUP. Reciclagem a frio: tecnologia de reciclagem a Frio Wirtgen. 1. ed.

Windhagen: Wirtgen GmgH, 2012. Disponível em: https://www.wirtgen-

group.com/media/02 wirtgen/05 pdfs/praxisratgeber leseproben/manual cold-

recycling excerpt pt.pdf. Acesso em: dez. 2017. 